\title{
Finite Element Simulation of Three Full-Scale Crash Tests for Cessna 172 Aircraft
}

\author{
Brian H. Mason* and Jerry E. Warren, Jr. ${ }^{\dagger}$ \\ NASA Langley Research Center, Hampton, VA, 23681-2199
}

The NASA Emergency Locator Transmitter Survivability and Reliability (ELT-SAR) project was initiated in 2013 to assess the crash performance standards for the next generation of emergency locator transmitter (ELT) systems. Three Cessna 172 aircraft were acquired to perform crash testing at NASA Langley Research Center's Landing and Impact Research Facility. Full-scale crash tests were conducted in the summer of 2015 and each test article was subjected to severe, but survivable, impact conditions including a flare-to-stall during emergency landing, and two controlled-flight-intoterrain scenarios. Full-scale finite element analyses were performed using a commercial explicit solver, ABAQUS. The first test simulated impacting a concrete surface represented analytically by a rigid plane. Tests 2 and 3 simulated impacting a dirt surface represented analytically by an Eulerian grid of brick elements using a Mohr-Coulomb material model. The objective of this paper is to summarize the test and analysis results for the three fullscale crash tests. Simulation models of the airframe which correlate well with the tests are needed for future studies of alternate ELT mounting configurations.

\section{Introduction}

\section{A. Motivation and Background}

In 2013, the NASA Search and Rescue (SAR) Mission Office at Goddard Space Flight Center (GSFC) initiated a study to assess the crash performance standards of the next generation of Emergency Locator Transmitters (ELT). In pursuit of this ELT-SAR study, three Cessna 172 aircraft were acquired by NASA and subjected to severe but survivable crash tests in the summer of 2015. The crash tests enable evaluation of ELT performance under conditions that more accurately replicate actual crash environments than those found in the current performance standard. Each aircraft was equipped with four to five ELTs. These crash tests were conducted at the Landing and Impact Research (LandIR, Ref. 1 and 2) facility at NASA Langley Research Center (LaRC). A photo of the LandIR is shown in Figure 1. The details of the test set up and rigging are fully documented in Ref. 3 . The data from the three tests were used to calibrate structural finite element (FE) models of the airframes. Once calibrated, these models can be

\footnotetext{
*Research Aerospace Engineer, Durability, Damage Tolerance, and Reliability Branch, Senior Member AIAA 'Research Aerospace Engineer, Structural Dynamics Branch, Member AIAA
} 
used to predict the airframe and ELT responses at various aircraft impact conditions. The analyses will lead to updated installation standards for the entire ELT system (beacon, antenna and interconnecting cabling).

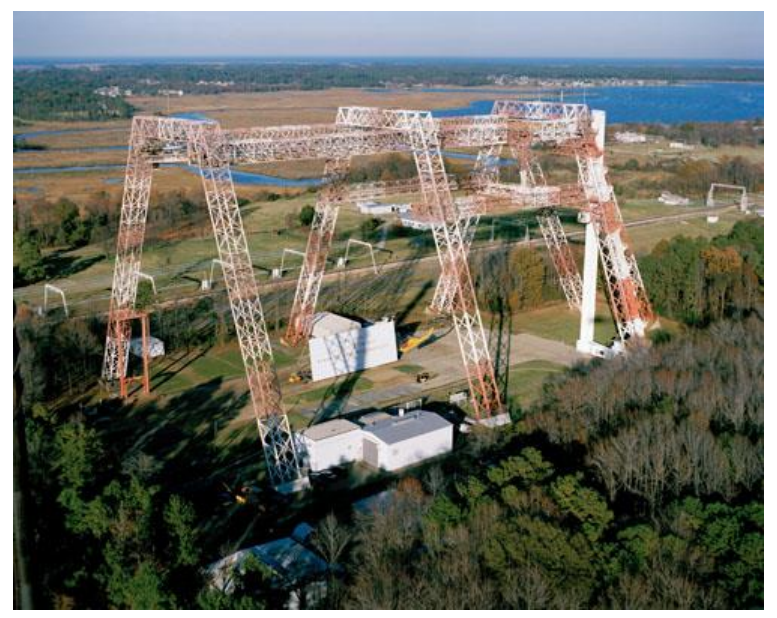

Figure 1. NASA Landing and Impact Research (LandIR) facility.

Beginning in the mid-1970s, the LandIR facility at LaRC was used for testing General Aviation (GA) aircraft for improved crashworthiness (Ref. 4 to 11). Data from tests conducted between 1974 and 1983 were used to assist the Federal Aviation Administration (FAA) in establishing seat certification standards (Ref. 12). The Advanced General Aviation Transport Experiments (AGATE) program was established in the late 1990s as a collaboration between government and industry to revive the GA market. Full-scale crash tests of a Beech Starship in 1995 and a modified Lancair aircraft in 2001 were performed as technology demonstrations for AGATE (Ref. 13 and 14). LandIR is a unique facility that is well suited for performing the general aviation aircraft crash tests planned by the ELT-SAR project.

The Cessna 172 Skyhawk is a four-seat, single engine, high-wing airplane, manufactured by the Cessna Aircraft Company. More Cessna 172s (over 43,000 airframes) have been built than any other aircraft and the first production models were delivered in 1956. These aircraft were selected for this series of crash tests for their availability and because ELT performance does not vary significantly from one general aviation aircraft to another. It is also noted that NASA had previously conducted a series of crash tests using C-172 aircraft in the 1970s (Ref. 15 and 8), and these tests helped to guide the development of the lifting hardware used in the current tests. 


\section{B. Test Description}

The three Cessna high-wing, four seat, GA airplanes used for this test series are shown in Figure 2. Test article 1 was a $1958 \mathrm{C}-172$. Test article 2 was a $1958 \mathrm{C}-175$, which is built on the C-172 airframe, but contains a different engine and gearbox. The third test article was a $1975 \mathrm{C}-$ 172M. Test articles 1 and 3 were operational until the winter of 2014 before their purchase by NASA LaRC.

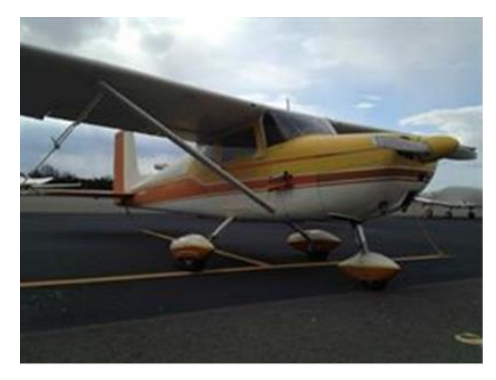

Test article 1

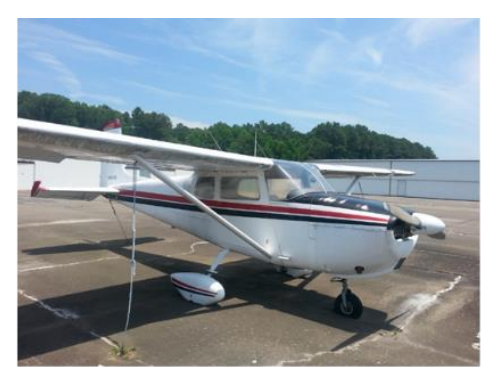

Test article 2

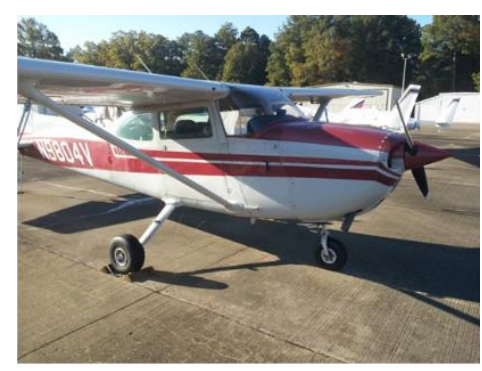

Test article 3

Figure 2. ELTSAR crash test articles.

Each aircraft was outfitted with similar instrumentation, cameras, and onboard experiments. Multiple ELTs were mounted into the cabin or tail section of each aircraft for the evaluation of their performance. The rear seats and luggage area equipment were removed from each airplane, and an onboard data acquisition system (DAS) was installed in their place. The DAS recorded accelerations throughout the fuselage at a sampling rate of $10 \mathrm{kHz}$. A frame assembly was constructed on the top of the wing for rigging the airframe to the LandIR facility. Further information about the instrumentation and rigging hardware for the tests is presented in Ref. 3.

All tests were conducted within the approximate stall speed of the aircraft. Test 1 was designed to simulate a flare-to-stall onto a rigid surface (concrete). This case provided a way to isolate the airframe response for model calibration. Tests 2 and 3 were designed to simulate controlled-flight-into-terrain conditions, where the terrain response must also be accounted for in the models. Test 2 featured the airplane impacting with a nose down condition, while Test 3 featured the airplane impact with a nose up and tail strike condition. Tests 2 and 3 impacted a dirt surface consisting of a clay-sand mixture, and is known as Gantry Unwashed Sand (GUS) (Ref. 16). This soil was recently used as the impact surface for the TRACT full-scale tests (Ref. 
17). Preliminary analytical results for the 3 crash tests were presented in Ref. 18. Analytical results from LS-DYNA simulations of crash tests 1 and 2 are presented in Refs. 19 and 20, respectively. In Table 1, the as-measured impact conditions are presented. In Table 1, the horizontal and vertical directions are defined as normal and parallel to the ground, respectively.

Table 1. Crash conditions at impact.

\begin{tabular}{|c|c|c|c|c|c|} 
Test & Surface & $\begin{array}{c}\text { Vertical Velocity } \\
\text { (inch/s) }\end{array}$ & $\begin{array}{c}\text { Horizontal Velocity } \\
\text { (inch/s) }\end{array}$ & $\begin{array}{c}\text { Pitch Angle } \\
\text { (deg) }\end{array}$ & $\begin{array}{c}\text { Pitch Rate } \\
\text { (deg/s) }\end{array}$ \\
\hline 1 & Concrete & 276.0 & 772.8 & +1.48 & +16.5 \\
\hline 2 & GUS & 344.4 & 892.8 & -12.20 & +16.1 \\
\hline 3 & GUS & 283.2 & 739.2 & +8.0 & +13.1 \\
\hline
\end{tabular}

\section{Purpose and Contents}

The purpose of this paper is to correlate explicit dynamic FE simulation models with data from the experimental tests. Correlation of the models includes comparison of airframe weight, center of gravity, kinematic response, delta velocity, and accelerometer data between the simulation model and the experimental tests. Simulation models that represent the kinematic response of the airframe well can then be used to evaluate alternative ELT mounting configurations.

This paper is organized as follows. Section II provides a description of the computer models used to simulate the impact tests. In Section III, test results are compared to results from the computer simulations. A summary of the analysis techniques used in the paper and the conclusions of the study are presented in Section IV. 


\section{Model Geometry and Loads}

In this section, the computer models used to simulate the impact tests are described. The derivation of the geometry for the models is described first. Next, material properties for the model are discussed. In the third part of this section, the finite element (FE) model mesh representation is described.

\section{A. Geometry for Analytical Models}

Development of the FE models was complicated by the fact that no prior geometry or static load models of the C-172 airframe existed and no engineering drawings were available. Consequently, an original CAD (computer aided design) geometry of the airframe was generated using both a three-dimensional laser scan and hand measurements of the test article. The measurements were used as inputs to the Conceptual Design Shop (CDS) tool, an airframe geometry generation tool developed within the PATRAN FE modeling software (Ref. 21). Initial geometry from CDS was tuned to match the point cloud from the laser scan, as shown in Figure 3. The CDS-generated geometry included internal structure (ribs, spars, frames, etc.) of the airframe. The FE model was discretized from this geometry, although several additional structural components (ELTs, point masses, LandIR mounts) were added later.

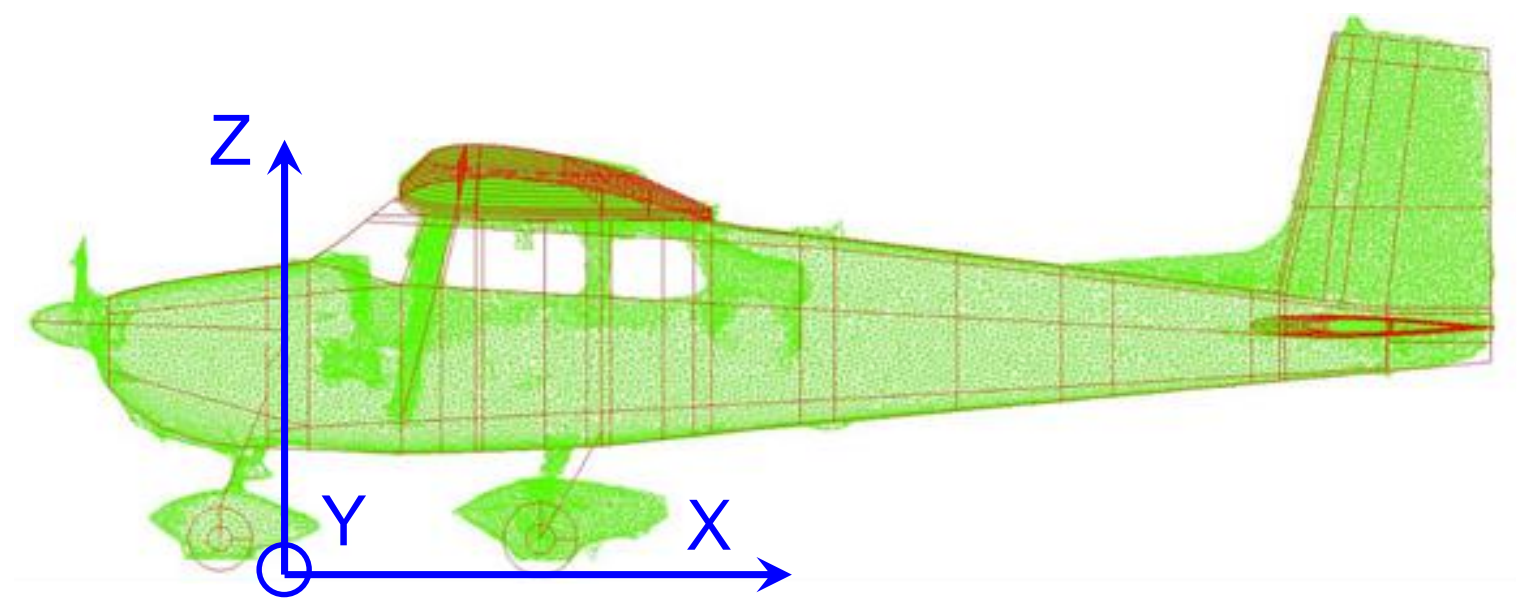

Figure 3. CDS geometry (red) and laser scanned data (green) for C-172 airframe.

Simulations for the Test 1 and 2 configurations used the same C-172 FE airframe model. For the Test $3 \mathrm{C}-172 \mathrm{M}$ airframe, the fuselage aft of frame 108 was replaced with the swept tail geometry, as shown in Figure 4. 


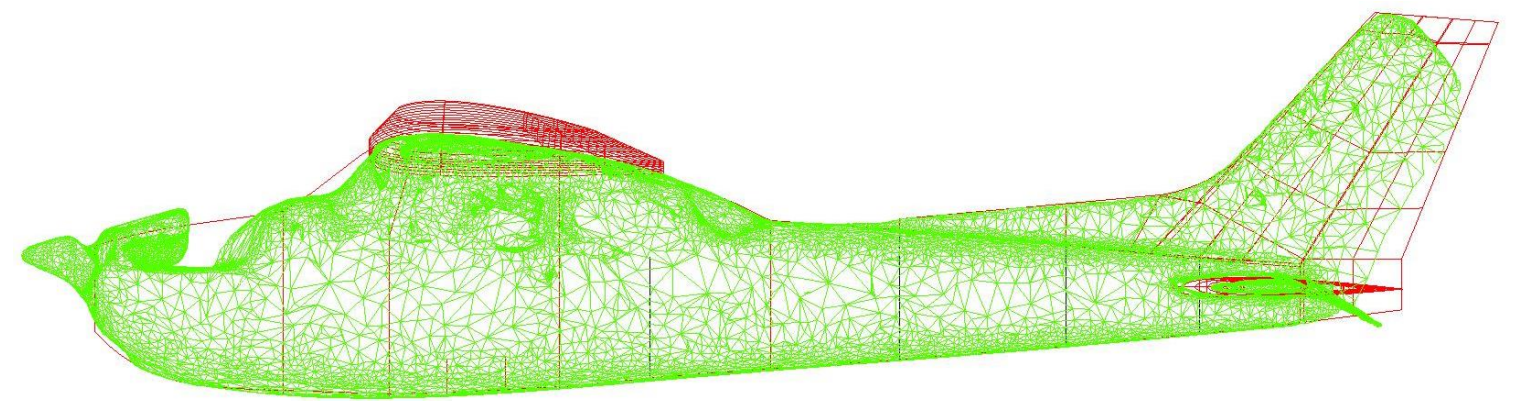

Figure 4. CDS geometry (red) and laser scanned data (green) for C-172M airframe.

\section{B. Material Properties}

Due to the lack of data from the manufacturer, the exact material properties and component dimensions (thicknesses, beam heights, rod diameters ...) were unknown. Because of the large number of components in the aircraft, extensive strength and stiffness testing of all components in the aircraft was not practical, so the material properties commonly used in aircraft are assumed and given in Table 2. A magnet was used to determine that the engine mounts, landing gear, and firewall contained ferric steel; all other metallic components were assumed to be constructed of aluminum. The engine and DAS boxes were not modeled in detail, but their average densities were tuned to match the measured weight. A series of hand measurements were taken of the panel thicknesses at key locations in the aircraft (forward fuselage, aft fuselage, rib, spar, and wing covers, etc.). The shock absorber in the nose landing gear is represented by a slot connector element using the load displacement curve shown in Figure 5. The shock properties in Figure 5 were derived from the aircraft gross take-off weight (GTOW) and the weight supported by the nose wheel when the aircraft is at rest.

Table 2. Material elastic properties.

\begin{tabular}{|c|c|c|c|c|}
\hline & $\begin{array}{c}\text { Elastic modulus } \\
(\mathbf{M s i})\end{array}$ & Poisson's ratio, $\boldsymbol{v}$ & $\begin{array}{c}\text { Mass Density } \\
\left(\mathbf{l b f}^{\mathbf{2}} / \mathbf{i n c h}^{\mathbf{4}}\right)\end{array}$ & $\begin{array}{c}\text { Yield Stress } \\
(\mathbf{k s i})\end{array}$ \\
\hline Steel & 30.000 & 0.300 & $7.359 \times 10^{-4}$ & 90.0 \\
\hline Aluminum & 10.000 & 0.300 & $2.525 \times 10^{-4}$ & 40.0 \\
\hline Rubber & 0.357 & 0.323 & $2.588 \times 10^{-4}$ & 15.0 \\
\hline Glass & 0.500 & 0.300 & $1.124 \times 10^{-4}$ & $\mathrm{n} / \mathrm{a}$ \\
\hline
\end{tabular}




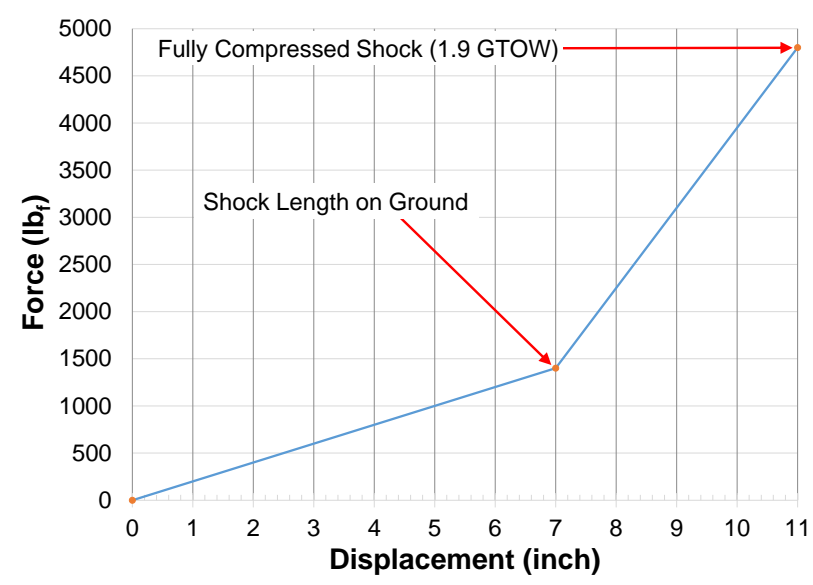

Figure 5. Derived load-displacement curve for nose landing gear shock.

Final tuning of the mass of the computer models to the actual aircraft was accomplished through the use of point masses. For Test 1, four point masses (totaling $220 \mathrm{lb}_{\mathrm{f}}$ ) were added to the model to match the weight and CG (center of gravity) of the test article, as shown in Table 3. The coordinate system for the model is shown in Figure 3. The Test 2 configuration is heavier than Test 1, and two point masses (totaling $321 \mathrm{lb}_{\mathrm{f}}$ ) were added to the model to match the weight and CG of the test article, as shown in Table 4. For Test 3, four point masses (totaling $393 \mathrm{lb}_{\mathrm{f}}$ ) were added to the model to match the weight and CG of the test article, as shown in Table 5.

Table 3. Test and analysis values of inertial properties for Test 1.

\begin{tabular}{|c|r|r|r|c|}
\hline Parameter & \multicolumn{1}{|c|}{ Test } & \multicolumn{1}{c|}{ Model } & Difference & \% Diff \\
\hline Weight, $\mathbf{l b}_{\mathbf{f}}$ & 2000.000 & 2000.013 & 0.013 & 0.001 \\
\hline $\mathbf{C G}_{\mathbf{x}}$, inch & 44.500 & 44.500 & 0.000 & 0.000 \\
\hline $\mathbf{C G}_{\mathbf{y}}$, inch & 0.000 & -0.028 & -0.028 & n/a \\
\hline $\mathbf{C G}_{\mathbf{z}}$, inch & 46.250 & 46.428 & 0.178 & 0.385 \\
\hline
\end{tabular}

Table 4. Test and analysis values of inertial properties for Test 2.

\begin{tabular}{|c|r|r|r|c|}
\hline Parameter & \multicolumn{1}{c|}{ Test } & \multicolumn{1}{c|}{ Model } & Difference & \% Diff \\
\hline Weight, $\mathbf{l b}_{\mathrm{f}}$ & 2114.000 & 2113.986 & -0.014 & -0.001 \\
\hline $\mathbf{C G}_{\mathbf{x}}$, inch & 39.500 & 39.500 & 0.000 & 0.000 \\
\hline $\mathbf{C G}_{\mathbf{y}}$, inch & 0.000 & -0.088 & -0.088 & $\mathrm{n} / \mathrm{a}$ \\
\hline $\mathbf{C G}_{\mathbf{z}}$, inch & 48.100 & 48.100 & 0.000 & 0.00 \\
\hline
\end{tabular}

Table 5. Test and analysis values of inertial properties for Test 3.

\begin{tabular}{|l|r|r|r|c|}
\hline Parameter & \multicolumn{1}{|c|}{ Test } & \multicolumn{1}{c|}{ Model } & Difference & \% Diff \\
\hline Weight, $\mathbf{l b}_{\mathrm{f}}$ & 2072.000 & 2071.980 & -0.020 & -0.001 \\
\hline $\mathbf{C G}_{\mathbf{x}}$, inch & 42.500 & 42.500 & 0.000 & 0.001 \\
\hline $\mathbf{C G}_{\mathbf{y}}$, inch & 0.000 & 0.073 & 0.073 & $\mathrm{n} / \mathrm{a}$ \\
\hline $\mathbf{C G}_{\mathbf{z}}$, inch & 50.800 & 50.601 & -0.199 & -0.392 \\
\hline
\end{tabular}




\section{Analysis Models}

All FE analyses are performed with the ABAQUS software, a product of Simulia (Ref. 22): The ABAQUS model representing the Test 1 configuration is shown in Figure 6. A nominal shell element edge length of 1.5-inch was used. This model contains 71,514 nodes, 235 beam elements, 74,640 shell elements, 400 solid elements, 66 multi-point constraints, 4 different materials, 4 revolute connectors (wheel axles), and 22 concentrated masses. The concrete impact surface was modeled as a horizontal rigid shell element, located 0.1-inches below the model. All shell elements were defined as ABAQUS S3R and S4R elements, and beam elements were defined with ABAQUS B31 elements. The four ELTs, DAS box, and tires were modeled as C3D8 solid elements. The engine, seats, dummy occupants, and fuel in the wing were simulated as concentrated masses. The model required 4.5 hours of wall clock time on an 8-processor Windows 7 workstation using ABAQUS/Explicit version 6.14 to simulate 0.30 -seconds of impact.

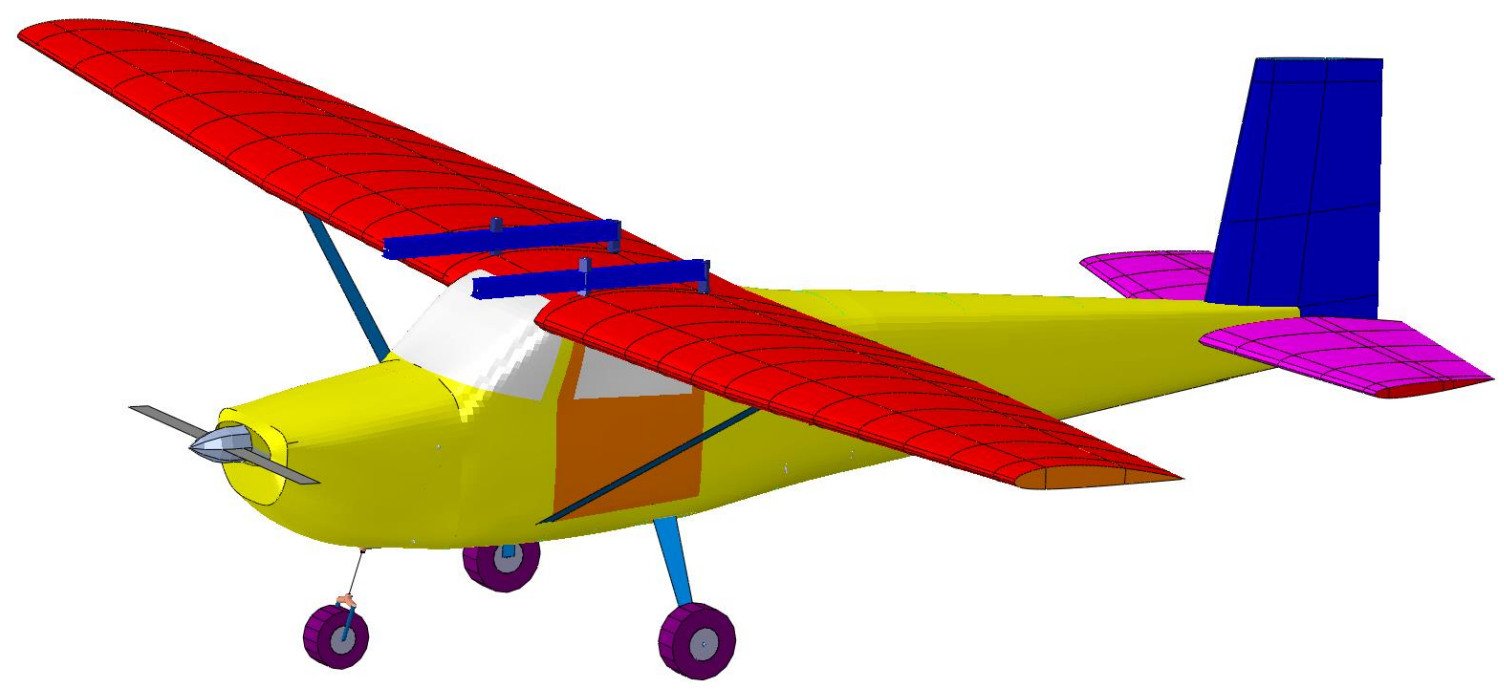

Figure 6. ABAQUS Model of C-172 airframe (Test 1 and 2).

The ABAQUS model representing the Test 2 configuration is identical to the Test 1 configuration with the following exceptions. First, the number and position of the ELTs (five instead of four) is different. Second, the nose landing gear shock in the test article was damaged and locked in place; so the spring shock used to represent the landing gear in Test 1 is replaced

\footnotetext{
* The use of trademarks or names of manufacturers in this report is for accurate reporting and does not constitute an official endorsement, either expressed or implied, of such products or manufacturers by the National Aeronautics and Space Administration.
} 
with a 1 inch long rigid beam. This beam is set up to break when the bending moment exceeds $240,000 \mathrm{lb}_{\mathrm{f}}$-inch to simulate failure of the nose gear observed during the test. And finally, the impact surface in Test 2 is soil (24-inch deep), which is modeled in ABAQUS with an Eulerian grid of 38,400 eight-node brick elements measuring 4 inch long by 3 inch wide by 2.5 inch deep. Soil properties are represented with the Mohr-Coulomb plasticity model with a density of $1.86 \times 10^{-4} \mathrm{lb}_{\mathrm{f}}-\mathrm{s}^{2} / \mathrm{inch}^{4}$ and a friction angle of 30-degrees. The model required 20 hours of wall clock time on an 8-processor Windows 7 workstation using ABAQUS/Explicit version 6.14 to simulate 0.30 -seconds of impact, which is noticeably higher than the Test 1 runtime due to the additional soil elements and contact with the soil.

The ABAQUS model representing the Test 3 configuration is shown in Figure 7. A nominal shell element edge length of 1.5 inch was used. This model contains 68,133 nodes, 331 beam elements, 69,064 shell elements, 976 solid elements, 42 multi-point constraints, 8 materials, 4 revolute connectors (wheel axles), and 24 concentrated masses. Major components (wing, fuselage, empennage, landing gear, etc.) are represented with the same types of elements as described for Test 1 . The impact surface in Test 3 is soil (24 inches deep), which is modeled in ABAQUS with 63,360 eight-node brick elements measuring 4 inch long by 3 inch wide by 2.5 inch deep and uses the same properties as given for Test 2. Rigid pins connecting the forward and aft fuselage are set up to break when the tensile reaction forces exceed $1000 \mathrm{lb}_{\mathrm{f}}$. For all analyses, nodal location-, velocity-, and acceleration-time histories at accelerometer locations were extracted from the results file.

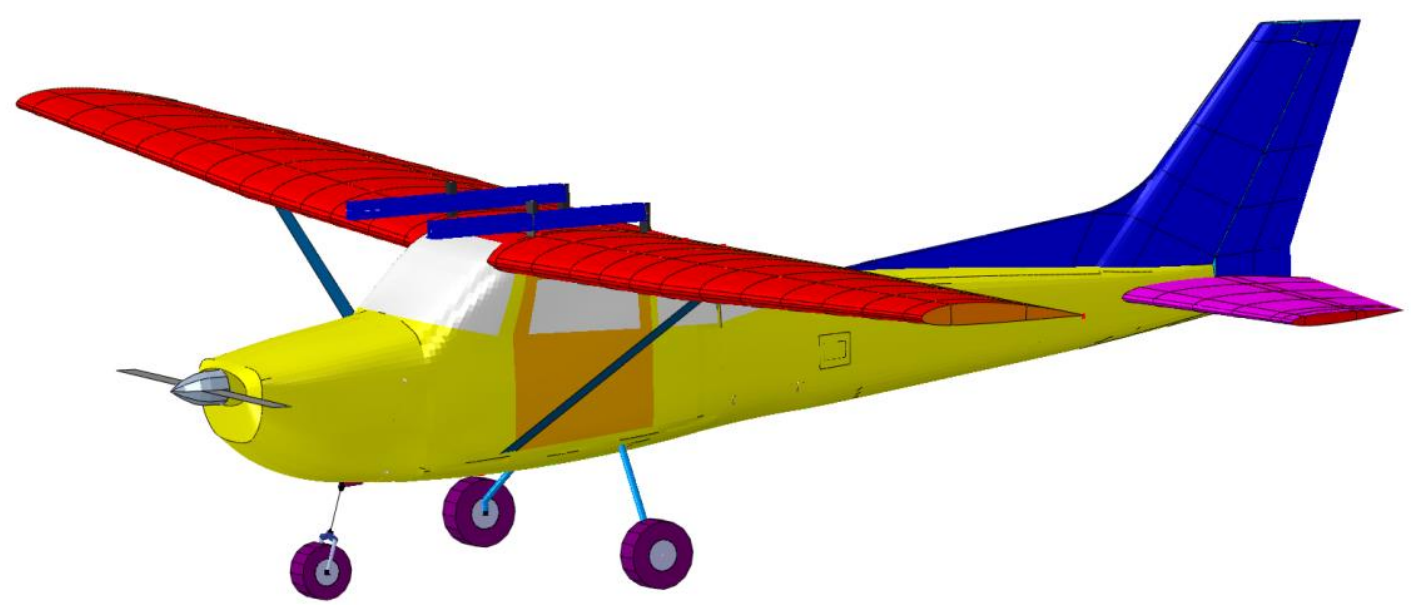

Figure 7. ABAQUS Model of C-172M airframe (Test 3). 


\section{Test and Analysis Correlation}

In this section, the results of FE simulations of crash Tests 1, 2, and 3 are presented and compared with experimental data.

\section{A. Crash Test 1}

A sequence of photographs taken from a high-speed camera is shown in Figure 8, along with corresponding views of the matching model kinematics. Overall, the simulation matches the gross kinematics of the test well; the difference in the tail impact was only about $0.01 \mathrm{sec}$. Pitch angle from photogrammetry during the test and simulation is plotted against time in Figure 9. Simulation data are collected at the accelerometers, and the closest accelerometer to the CG (where photogrammetry data were collected) is the pilot floor.

Main gear contact

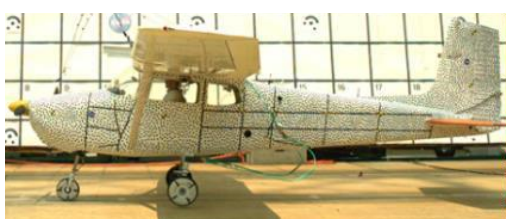

Time $=0.000 \mathrm{~s}$

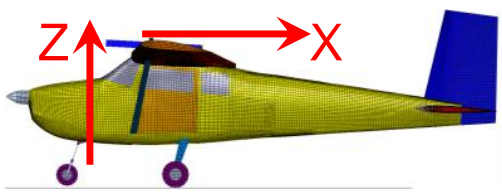

Time $=0.000 \mathrm{~s}$
Maximum spread of main gear

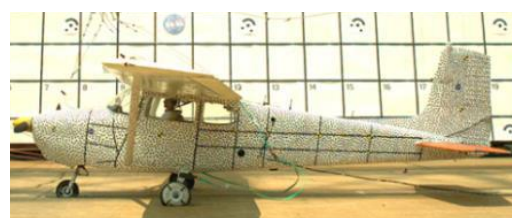

Time $=0.090 \mathrm{~s}$

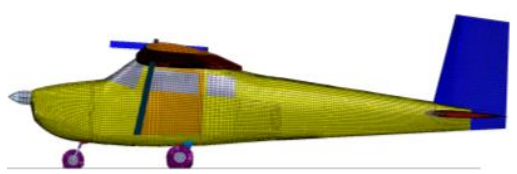

Time $=0.080 \mathrm{~s}$
Tail contact

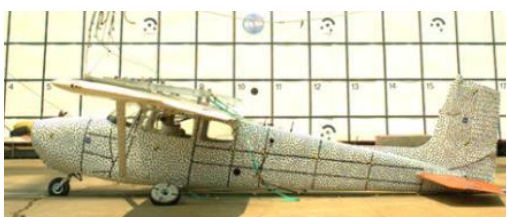

Time $=0.125 \mathrm{~s}$

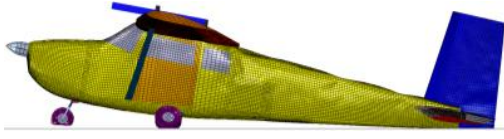

Time $=0.116 \mathrm{~s}$

Figure 8. Photographic images and computational models at critical kinematic events for Test 1.

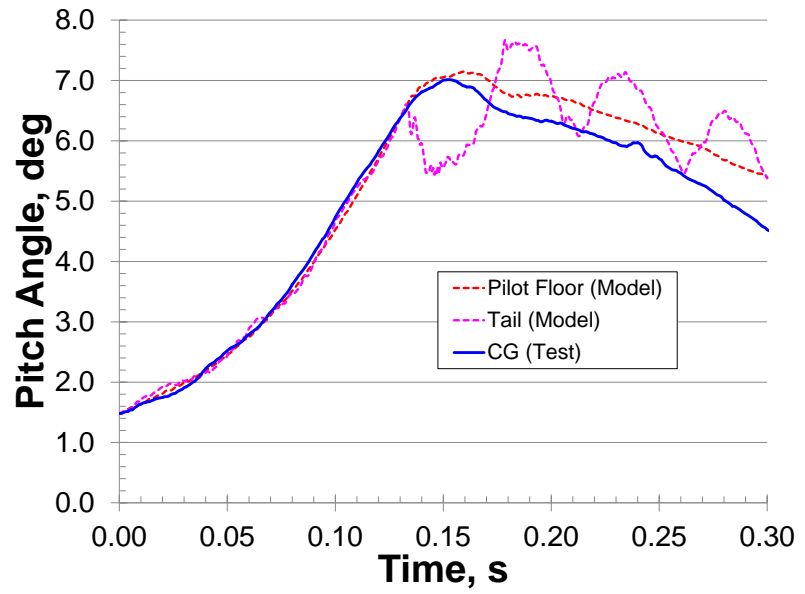

Figure 9. Pitch angle from test and simulation against time for two locations in Test 1. 
In Table 6, comparisons of test and analysis results of the rebound velocity (difference between impact velocity and minimum velocity, delta-V), average acceleration, and peak acceleration in the vertical $(Z)$ direction at several locations in the airframe are presented. Only vertical accelerations are presented as the horizontal accelerations were low. Comparisons in the vertical (Z) coordinate system are presented for three selected locations in the airframe (left door frame, DAS box, and rear bulkhead) in Figure 10. Test and analytical acceleration data are filtered using an SAE Channel Filter Class (CFC) 20 low-pass filter (Ref. 23). Acceleration data are presented in the local (moving) reference frame of each accelerometer. Velocities are presented in the global coordinate system. Analytical accelerations and velocities are computed in the fixed global coordinate system. For comparison with test data, the analytical accelerations are translated into the moving local coordinate system. The photogrammetry data used to compute the pitch angles in Figure 9 are used to transform the accelerometer data into the local fixed coordinate system; these transformed accelerations are integrated to produce velocity time histories for the test.

In Table 6, a quantitative ranking system is used for evaluating test and analysis comparisons. Comparisons within $10 \%$ are classified as "excellent" and highlighted in green. Comparisons within $20 \%$ are classified as "good" and highlighted in yellow. Comparisons worse than $30 \%$ are called "poor" and highlighted in red.

Table 6. Comparison of test and analysis of vertical velocity and acceleration at several locations for Test 1 .

\begin{tabular}{|l|ccc|ccc|ccc|}
\hline & \multicolumn{3}{|c|}{ Average Acceleration, g } & \multicolumn{3}{c|}{ Peak Acceleration, g } & \multicolumn{3}{c|}{ Delta-V, in/s } \\
& Test & Model & \% Diff & Test & Model & \% Diff & Test & Model & \% Diff \\
\hline Pilot Z & 3.5 & 3.9 & $11.5 \%$ & 7.6 & 11.4 & $50.1 \%$ & 398.0 & 394.6 & $-0.9 \%$ \\
Copilot Z & 3.7 & 3.8 & $2.4 \%$ & 7.2 & 10.5 & $44.4 \%$ & 388.5 & 394.1 & $1.4 \%$ \\
Left Door Z & 3.8 & 4.0 & $4.9 \%$ & 10.4 & 13.3 & $27.4 \%$ & 401.7 & 410.1 & $2.1 \%$ \\
Right Door Z & 3.8 & 4.0 & $7.6 \%$ & 10.8 & 12.7 & $17.4 \%$ & 426.3 & 407.9 & $-4.3 \%$ \\
DAS Z & 4.2 & 4.0 & $-2.6 \%$ & 12.9 & 16.4 & $27.4 \%$ & 440.5 & 429.2 & $-2.6 \%$ \\
Tail Z & 4.8 & 5.4 & $12.1 \%$ & 37.2 & 51.7 & $38.7 \%$ & 514.5 & 503.2 & $-2.2 \%$ \\
Ceiling Z & 3.8 & 4.0 & $4.8 \%$ & 9.8 & 17.8 & $81.3 \%$ & 414.0 & 416.6 & $0.6 \%$ \\
Firewall Z & 3.9 & 4.1 & $4.6 \%$ & 8.7 & 8.4 & $-3.8 \%$ & 377.0 & 373.9 & $-0.8 \%$ \\
\hline
\end{tabular}



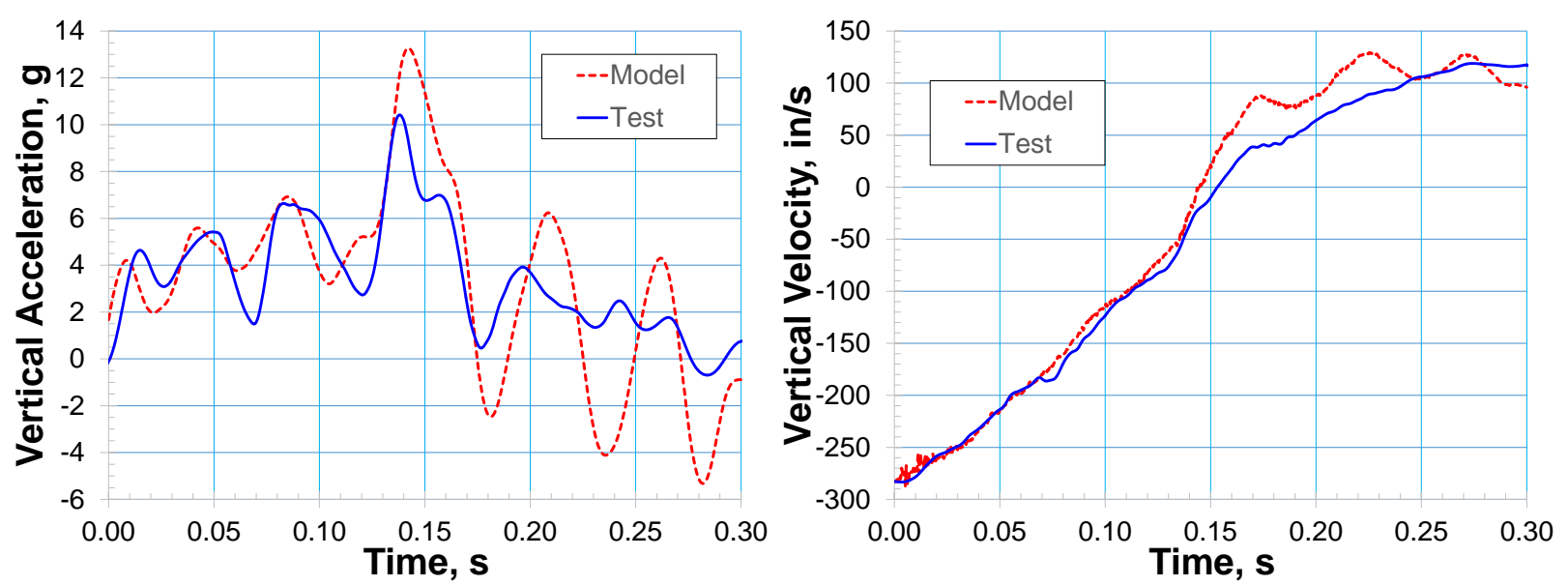

Left Door Frame
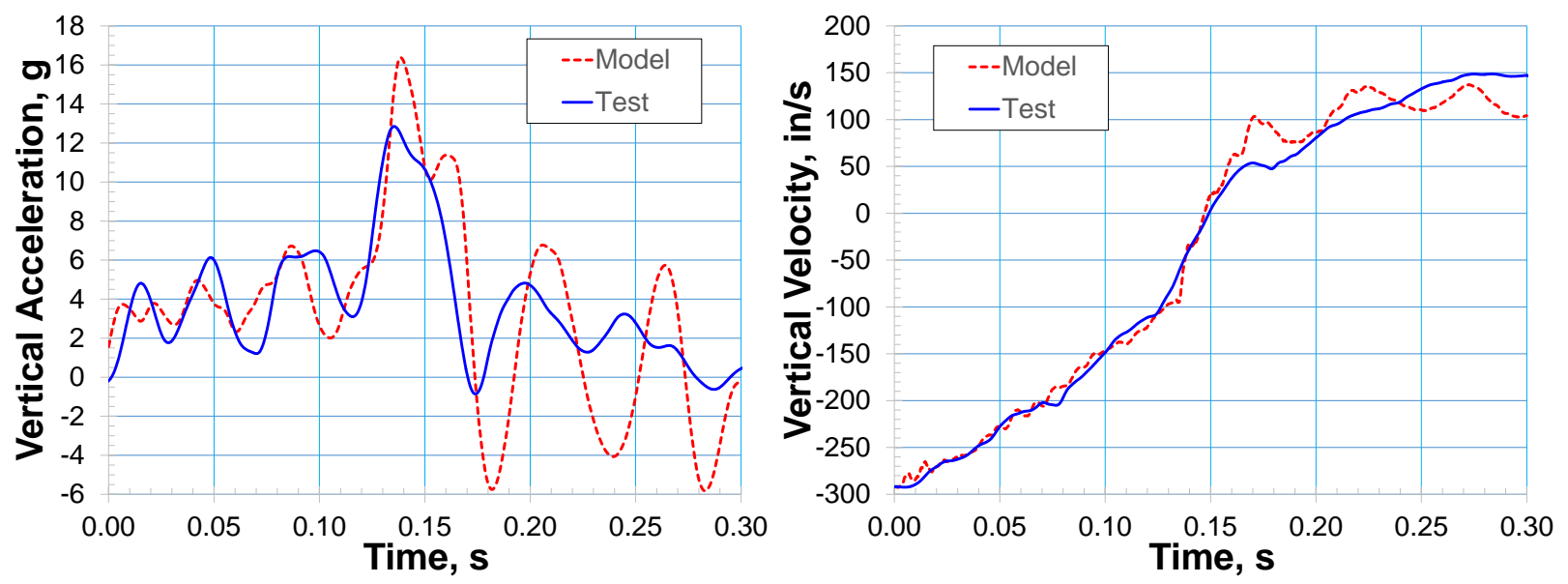

DAS Box
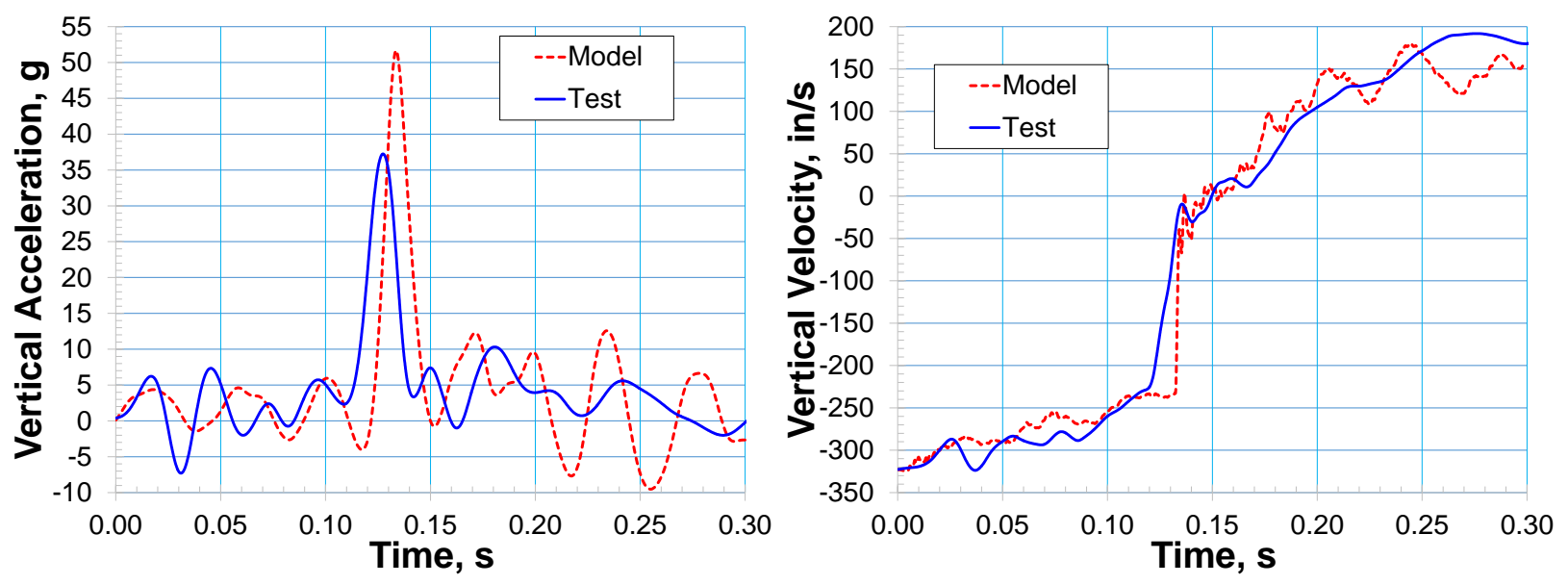

Rear Bulkhead

Figure 10. Test and analysis results of local vertical acceleration and global vertical velocity against time for three locations in Test 1. 
Test and analysis comparisons of the delta-velocity and average accelerations in the airframe are excellent; but comparisons are generally poor for the peak accelerations. Contributors to the difference in the test and simulated accelerations include uncertainties in the timing of events and the analytically perfectly rigid impact surface. Peak accelerations are also significantly affected by uncertainties in component thicknesses and weight distributions (which could not be easily measured) and lack of detail in modeling components in the vicinity of the accelerometers (such as the DAS box, the unmodeled seats, and unmodeled anthropomorphic test dummies)

\section{B. Crash Test 2}

A sequence of photographs taken from the high-speed camera is shown in Figure 11, along with corresponding views of the matching model kinematics. Note that the simulation model is cut in half to show the internal structure and the nose gear soil penetration. Pitch angle from photogrammetry during the test and simulation is plotted against time in Figure 12. The simulation predicts a nose-down rotation of the aircraft at 0.03 seconds after impact, about 0.10 seconds earlier than the rotation occurs in the test. Buckling of the aft tail section also occurs significantly earlier in the simulation than in the test; however, the rate of bending of the aft tail section after initiation of buckling is similar. In the test, the airframe maintains an almost constant pitch angle for 0.12 seconds after impact, suggesting that the modeled soil may be too stiff and is causing the nose gear of the model to dig in and flip the aircraft sooner than the test.

Nose gear contact

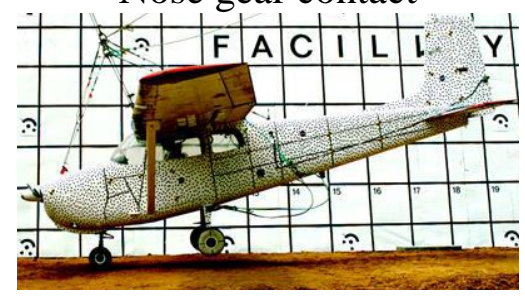

Time $=0.000 \mathrm{~s}$

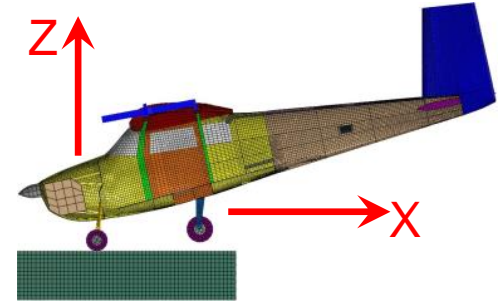

Time $=0.000 \mathrm{~s}$
Nose gear breakage

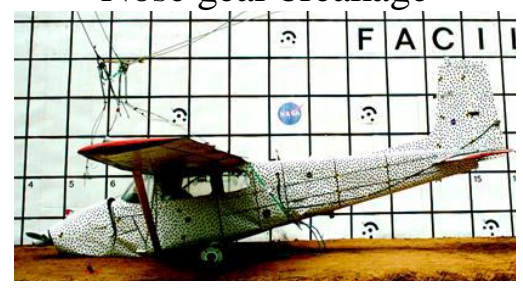

Time $=0.070 \mathrm{~s}$

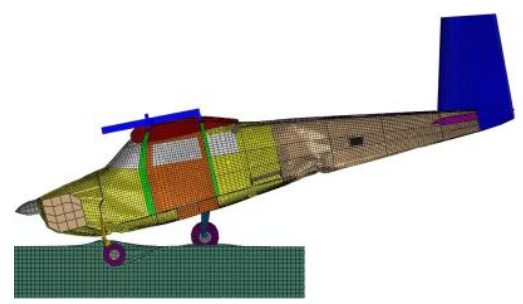

Time $=0.047 \mathrm{~s}$
Tail buckling initiation

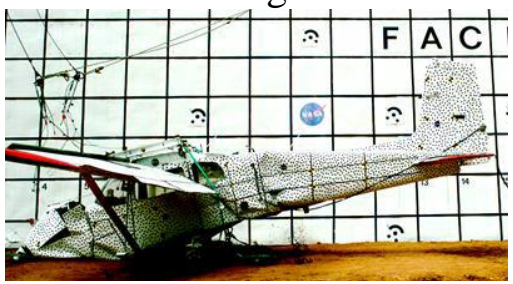

Time $=0.169 \mathrm{~s}$

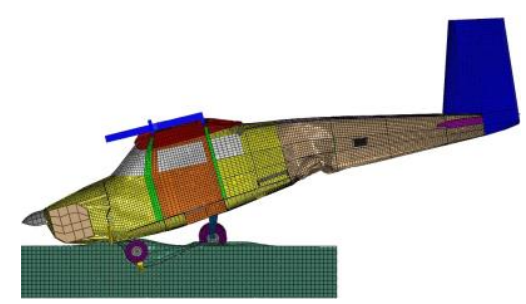

Time $=0.070 \mathrm{~s}$

Figure 11. Photographic images and computational models at critical kinematic events for Test 2. 


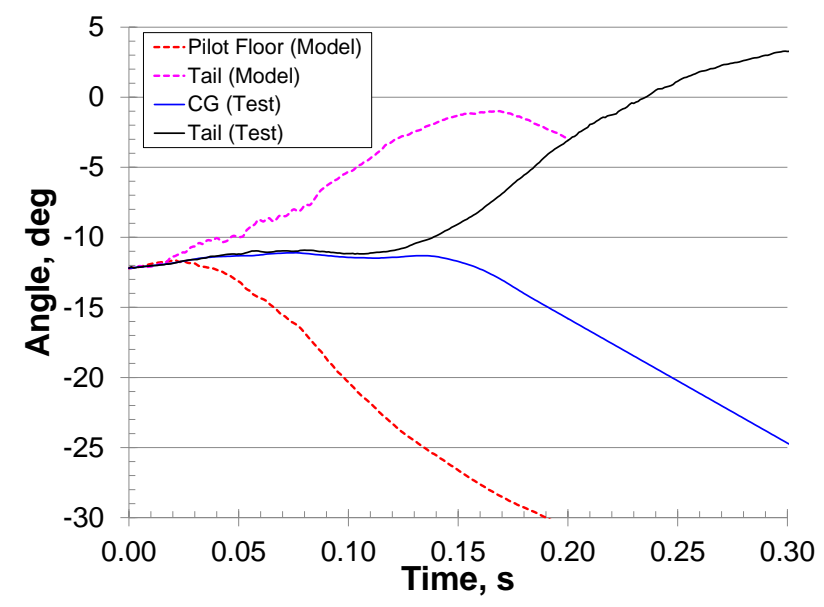

Figure 12. Pitch angle from test and simulation against time for two locations in Test 2 .

In Table 7, test and analysis comparisons of the delta-velocity, average acceleration, and peak acceleration for the horizontal $(\mathrm{X})$ and vertical $(\mathrm{Z})$ axes at several locations in the airframe are presented. Comparisons in the $\mathrm{Z}$ axis are presented for three selected locations in the airframe (left door frame, DAS box, and rear bulkhead) in Figure 13. Test and analytical acceleration data are filtered using an SAE CFC 20 low-pass filter and are presented in the local (moving) reference frame of each accelerometer. Velocities are presented in the global coordinate system.

Table 7. Comparison of test and analysis of velocity and acceleration in the $\mathrm{X}$ and $\mathrm{Z}$ axes at several locations for Test 2.

\begin{tabular}{|c|ccc|ccc|ccc|}
\hline & \multicolumn{3}{|c|}{ Average Acceleration, g } & \multicolumn{3}{|c|}{ Peak Acceleration, g } & \multicolumn{3}{c|}{ Delta-V, in/s } \\
& Test & Model & \% Diff & Test & Model & \% Diff & Test & Model & \% Diff \\
\hline Pilot X & -9.2 & -7.7 & $-16.2 \%$ & -23.5 & -21.7 & $-7.6 \%$ & 523.3 & 531.5 & $1.6 \%$ \\
Copilot X & -9.3 & -7.6 & $-17.9 \%$ & -24.0 & -20.8 & $-13.1 \%$ & 512.5 & 520.5 & $1.6 \%$ \\
Left Door X & -9.3 & -8.1 & $-12.9 \%$ & -21.6 & -18.7 & $-13.5 \%$ & 455.4 & 510.4 & $12.1 \%$ \\
Right Door X & -6.7 & -8.1 & $20.9 \%$ & -23.5 & -18.3 & $-22.3 \%$ & 421.9 & 511.0 & $21.1 \%$ \\
DAS X & -8.8 & -10.0 & $12.8 \%$ & -33.5 & -30.8 & $-8.1 \%$ & 412.9 & 466.5 & $13.0 \%$ \\
Tail X & -7.6 & -8.1 & $6.0 \%$ & -15.4 & -16.5 & $6.8 \%$ & 325.7 & 354.8 & $8.9 \%$ \\
Ceiling X & -7.4 & -9.5 & $28.2 \%$ & -16.5 & -18.9 & $14.2 \%$ & 319.8 & 373.8 & $16.9 \%$ \\
\hline Pilot Z & 5.2 & 5.4 & $3.3 \%$ & 15.9 & 12.9 & $-19.3 \%$ & 475.1 & 518.6 & $9.2 \%$ \\
Copilot Z & 5.0 & 5.8 & $15.6 \%$ & 19.2 & 16.2 & $-15.5 \%$ & 444.7 & 504.6 & $13.5 \%$ \\
Left Door Z & 7.5 & 9.0 & $19.7 \%$ & 28.3 & 14.0 & $-50.6 \%$ & 583.4 & 570.2 & $-2.3 \%$ \\
Right Door Z & 8.4 & 8.3 & $-1.6 \%$ & 19.1 & 14.1 & $-26.0 \%$ & 490.9 & 519.1 & $5.7 \%$ \\
DAS Z & 9.4 & 8.7 & $-6.9 \%$ & 21.1 & 24.4 & $15.5 \%$ & 686.1 & 625.3 & $-8.9 \%$ \\
Tail Z & 8.5 & 10.9 & $28.0 \%$ & 13.0 & 24.8 & $91.3 \%$ & 529.9 & 528.5 & $-0.3 \%$ \\
Ceiling Z & 7.9 & 7.3 & $-7.9 \%$ & 24.2 & 17.3 & $-28.7 \%$ & 549.5 & 528.7 & $-3.8 \%$ \\
\hline
\end{tabular}



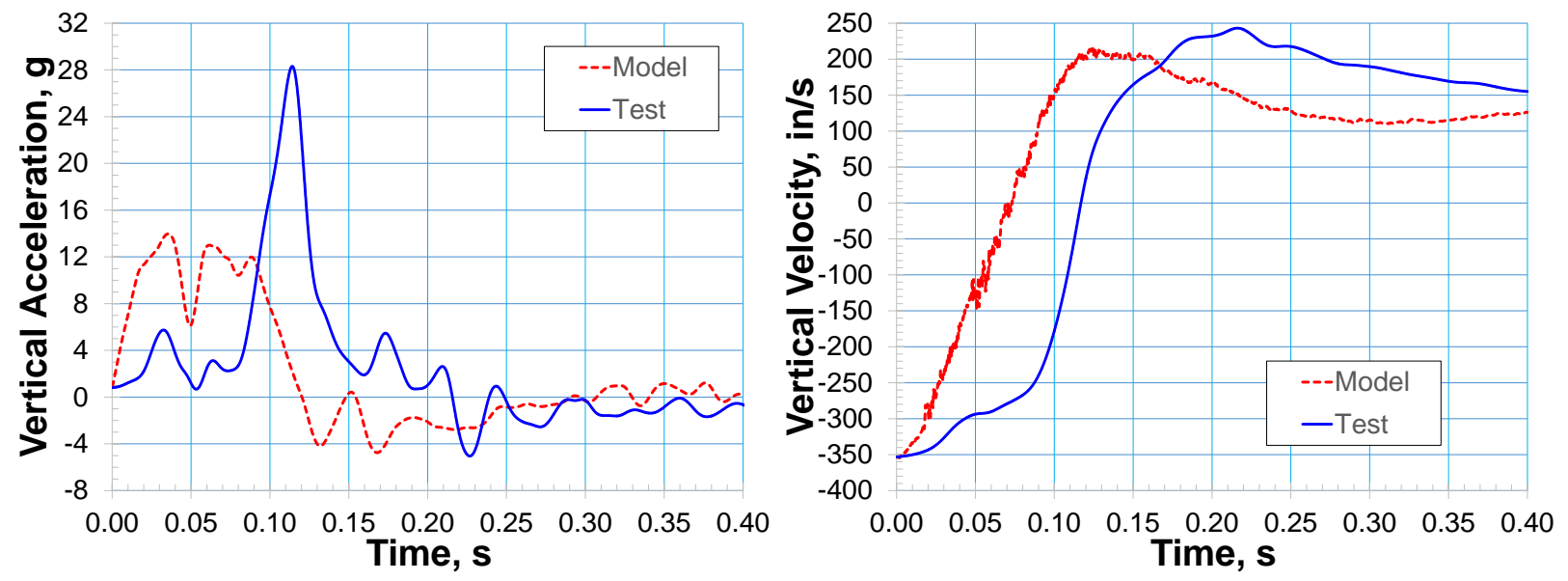

Left Door Frame
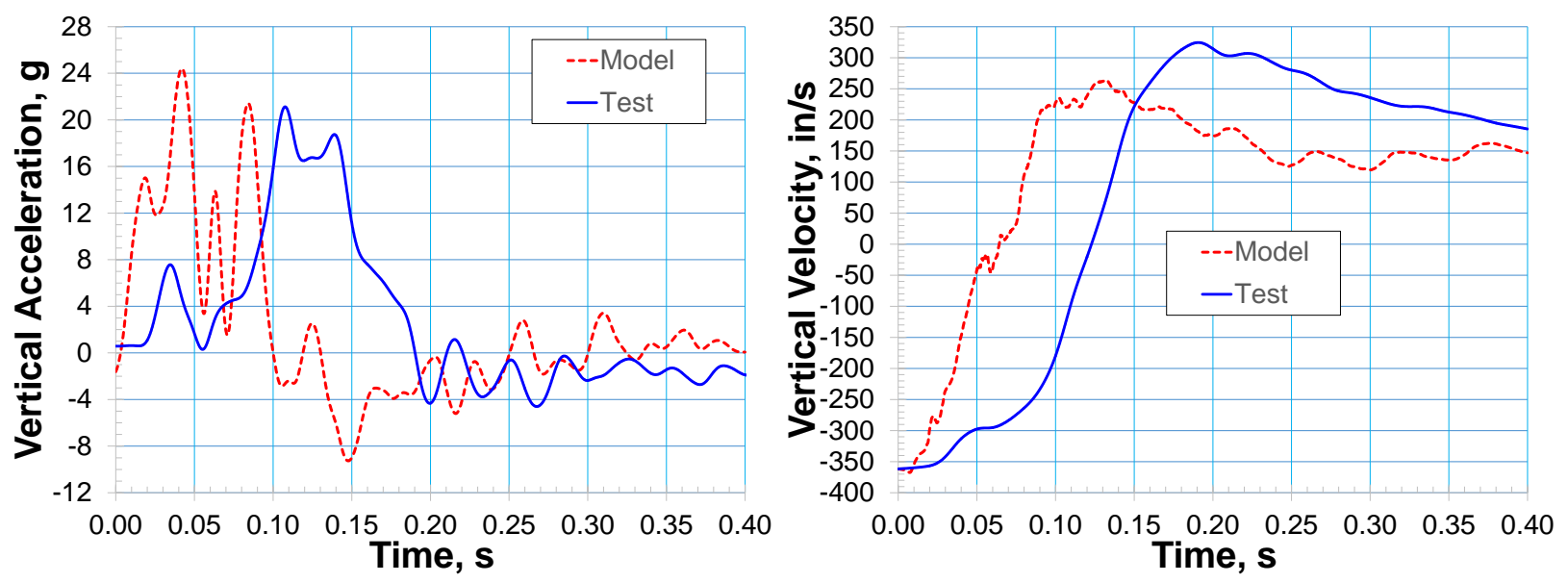

DAS Box
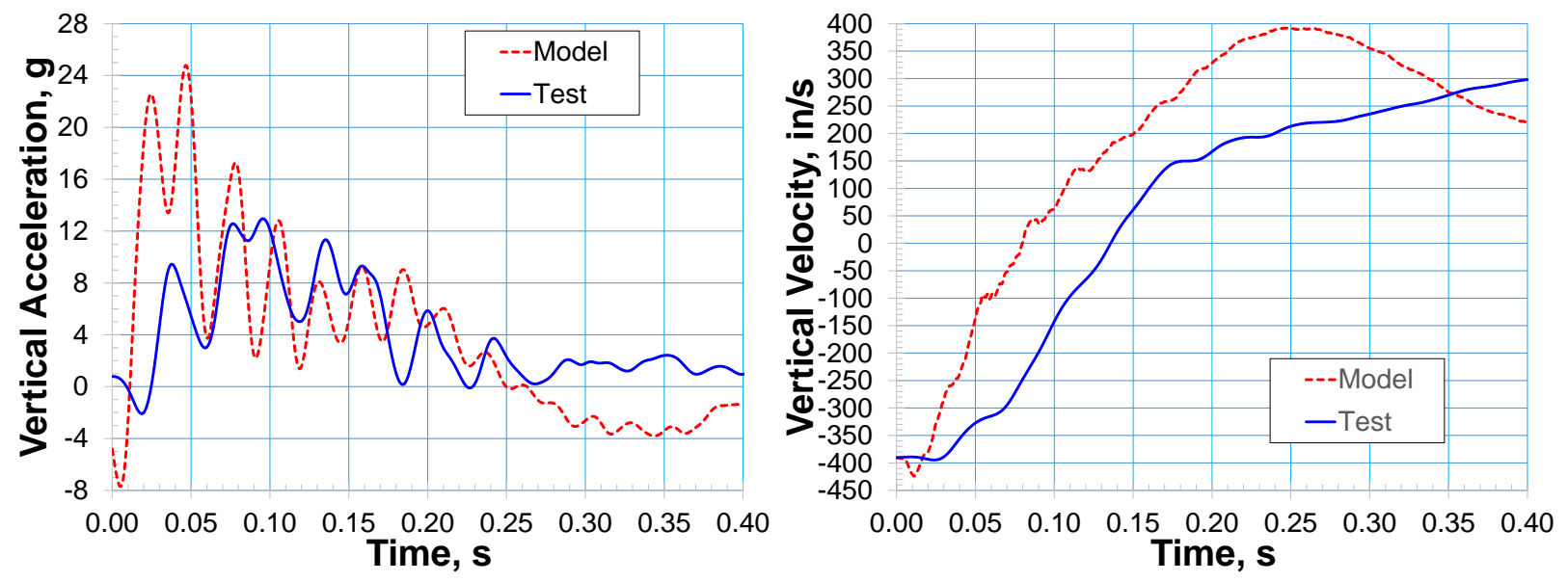

Rear Bulkhead

Figure 13. Test and analysis results of local vertical acceleration and global vertical velocity against time for three locations in Test 2. 
Test and analysis comparisons in Table 7 of the delta-velocity and average accelerations in the airframe are good to excellent. The test and model delta-velocities were within $21 \%$ at all accelerometer locations in the airframe, with most locations below 10\% difference. Comparison of the peak accelerations is good in the $\mathrm{X}$ direction but good to poor in the $\mathrm{Z}$ direction. The test and model peak accelerations were within $23 \%$ and $29 \%$ in the horizontal and vertical directions for all but two locations in the airframe. During the test, the left door opened, but this effect is not modeled and could contribute to the $50.6 \%$ difference in peak acceleration (which is also seen in the acceleration plot in Figure 13). Buckling in the tail section is particularly difficult to simulate and is significantly affected by even small differences in the fuselage geometry of the tail section and the weight distribution within the tail. These uncertainties in the geometry of the tail section are likely the major contributors to the $91.3 \%$ difference in the peak acceleration. Additionally, the Mohr-Coulomb model is a relatively simple material model and may not adequately represent the soil behavior. The simple Mohr-Coulomb model may contribute to the time difference (around $0.07 \mathrm{sec}$.) in the occurrence of the acceleration and velocity peaks in Figure 13, as described in the above discussion of the kinematic events.

\section{Crash Test 3}

A sequence of photographs taken from the high-speed camera is shown in Figure 14, along with corresponding views of the matching model kinematics. Note that the simulation model is cut in half to show the internal structure and the nose gear soil penetration. Pitch angle from photogrammetry during the test and simulation is plotted against time in Figure 15. The test and model pitch angle time histories matched closely for the first 0.05 seconds after impact, and remain within 4 degrees for the remainder of the photogrammetry data, but the tail separation angle is much more severe in the simulation. Additionally, in the simulation the cabin fuselage is not in contact with the ground at the time of tail failure as in the test. This delay in fuselage contact is probably due to a stiffness difference in the main landing gear, in the soil, or both. Overall, the motion of the forward fuselage in the simulation is similar to the test. 
Main gear contact

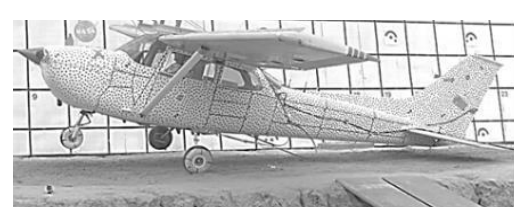

Time $=0.000 \mathrm{~s}$

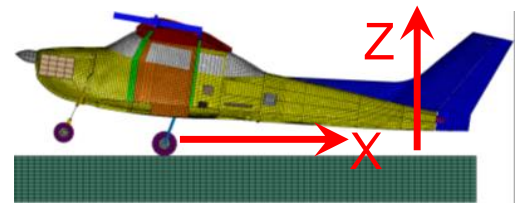

Time $=0.000 \mathrm{~s}$
Tail contact

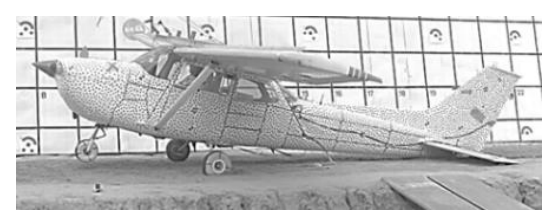

Time $=0.030 \mathrm{~s}$

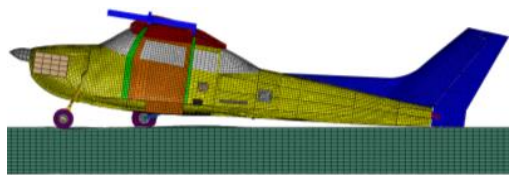

Time $=0.075 \mathrm{~s}$
Tail failure initiation

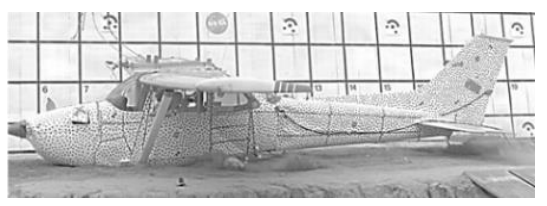

Time $=0.138 \mathrm{~s}$

Figure 14. Photographic images and computational models at critical kinematic events for Test 3.

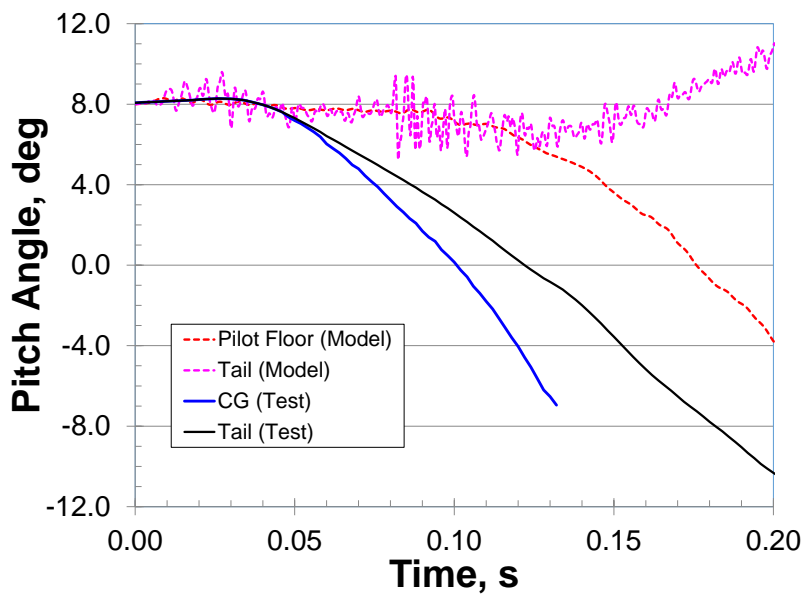

Figure 15. Pitch angle from test and simulation against time for two locations in Test 3.

In Table 8, comparison of test and analysis results of the delta-velocity, average acceleration, and peak acceleration for the $\mathrm{X}$ and $\mathrm{Z}$ axes at several locations in the airframe are presented. Comparisons in the $\mathrm{Z}$ axis are presented for three selected locations in the airframe (left door frame, DAS box, and rear bulkhead) in Figure 16. Test and analytical acceleration data are filtered using an SAE CFC 20 low-pass filter and are presented in the local (moving) reference frame of each accelerometer. Velocities are presented in the global coordinate system.

Test and analysis comparisons in Table 8 of the delta-velocities in the airframe are good to excellent (within 17\%) except in the tail due to the large damage that occurs there. The poor correlation in the tail is also seen in the delta-velocity plot in Figure 16. Correlation of the average and peak accelerations is good to excellent in the $\mathrm{Z}$ direction except at the damaged 
firewall (24\%). Also note that in Figure 16, timing of the acceleration and velocity peaks in the $\mathrm{Z}$ direction from the simulation and the test are close (within around $0.02 \mathrm{sec}$ ). In Table 8, correlation of the average and peak accelerations in the $\mathrm{X}$ direction is poor, probably because of the delay in the fuselage impact with the ground as described in the above discussion of the kinematic events. The delay in the simulation results in a reduction in the time that the belly of the fuselage is in contact with the soil, and hence, a reduction in the amount of horizontal deceleration due to friction between the fuselage and the soil. The delay could be due to uncertainty of the stiffness of the landing gear and uncertainty in definition of the zero-degree pitch angle of the model and the test article. Additionally, the Mohr-Coulomb model is a relatively simple material model and may not adequately represent the soil behavior.

Table 8. Comparison of test and analysis of velocity and acceleration in the $\mathrm{X}$ and $\mathrm{Z}$ axes at several locations for Test 3.

\begin{tabular}{|c|rrr|rrr|rrr|}
\hline & \multicolumn{3}{|c|}{ Average Acceleration, g } & \multicolumn{3}{|c|}{ Peak Acceleration, g } & \multicolumn{3}{c|}{ Delta-V, in/s } \\
& Test & Model & \% Diff & \multicolumn{1}{c|}{ Test } & \multicolumn{1}{c|}{ Model } & \% Diff & Test & Model & \% Diff \\
\hline Pilot X & -5.8 & -4.1 & $-30.1 \%$ & -16.8 & -10.9 & $-34.9 \%$ & 496.7 & 419.1 & $-15.6 \%$ \\
Copilot X & -6.3 & -4.0 & $-36.6 \%$ & -16.6 & -10.7 & $-35.6 \%$ & 504.0 & 418.7 & $-16.9 \%$ \\
Left Door X & -5.3 & -3.6 & $-31.4 \%$ & -14.9 & -10.9 & $-27.0 \%$ & 467.4 & 390.1 & $-16.5 \%$ \\
Right Door X & -5.5 & -3.8 & $-30.3 \%$ & -13.9 & -11.1 & $-20.0 \%$ & 437.8 & 390.9 & $-10.7 \%$ \\
DAS X & -5.2 & -3.4 & $-33.2 \%$ & -14.1 & -12.1 & $-13.9 \%$ & 365.5 & 363.0 & $-0.7 \%$ \\
Tail X & -4.4 & -3.4 & $-22.9 \%$ & -11.5 & -12.0 & $5.0 \%$ & 319.7 & 348.3 & $8.9 \%$ \\
Ceiling X & -4.0 & -2.1 & $-48.4 \%$ & -9.4 & -7.7 & $-17.9 \%$ & 255.3 & 234.6 & $-8.1 \%$ \\
Firewall X & -6.5 & -3.5 & $-45.7 \%$ & -22.0 & -9.6 & $-56.5 \%$ & 284.2 & 295.2 & $3.9 \%$ \\
\hline Pilot Z & 6.0 & 5.2 & $-13.0 \%$ & 16.6 & 13.5 & $-18.3 \%$ & 572.0 & 483.5 & $-15.5 \%$ \\
Copilot Z & 5.7 & 4.8 & $-16.3 \%$ & 15.7 & 14.1 & $-10.1 \%$ & 527.7 & 483.5 & $-8.4 \%$ \\
Left Door Z & 7.6 & 6.5 & $-14.5 \%$ & 17.5 & 16.8 & $-4.1 \%$ & 664.5 & 570.2 & $-14.2 \%$ \\
Right Door Z & 6.8 & 6.6 & $-4.0 \%$ & 20.2 & 16.4 & $-18.6 \%$ & 664.2 & 569.5 & $-14.3 \%$ \\
DAS Z & 8.1 & 7.1 & $-12.4 \%$ & 26.8 & 25.0 & $-6.6 \%$ & 723.7 & 690.3 & $-4.6 \%$ \\
Tail Z & 9.2 & 7.4 & $-19.7 \%$ & 32.5 & 31.4 & $-3.4 \%$ & 842.2 & 574.9 & $-31.7 \%$ \\
Ceiling Z & 6.3 & 6.3 & $0.8 \%$ & 19.8 & 21.0 & $6.2 \%$ & 598.1 & 555.3 & $-7.2 \%$ \\
Firewall Z & 6.6 & 5.0 & $-23.8 \%$ & 14.2 & 12.3 & $-13.5 \%$ & 357.9 & 335.2 & $-6.3 \%$ \\
\hline
\end{tabular}



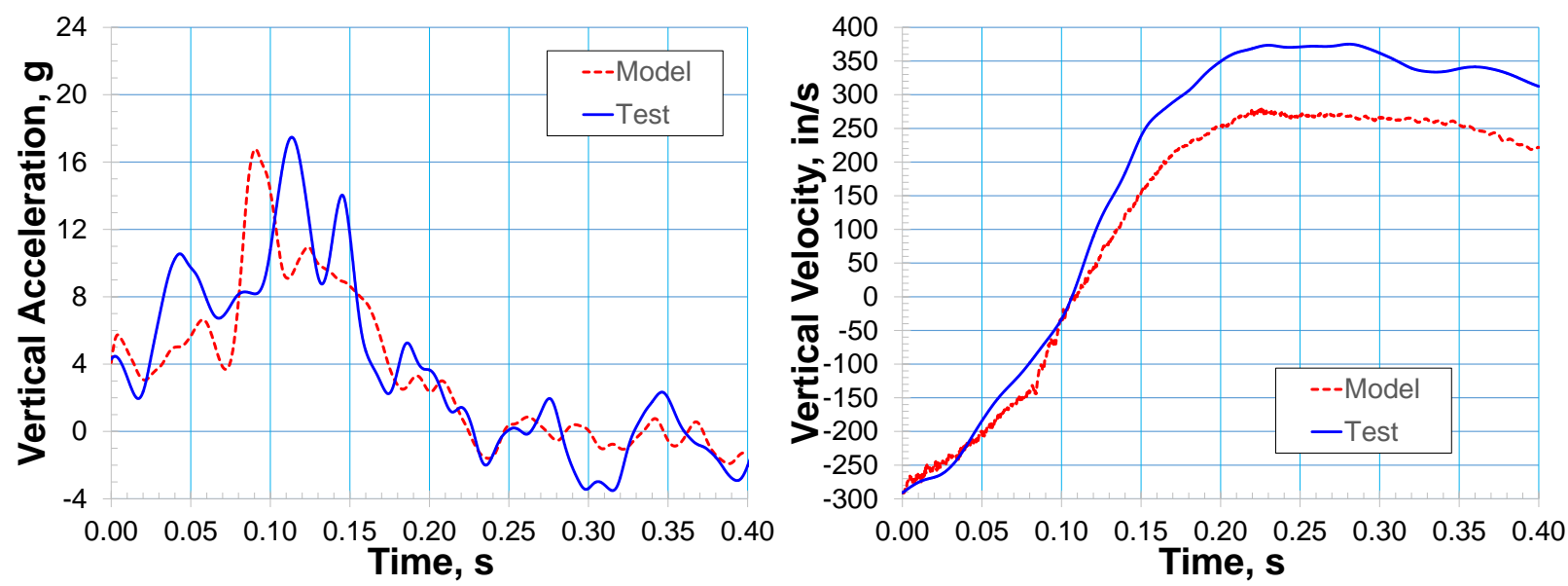

Left Door Frame
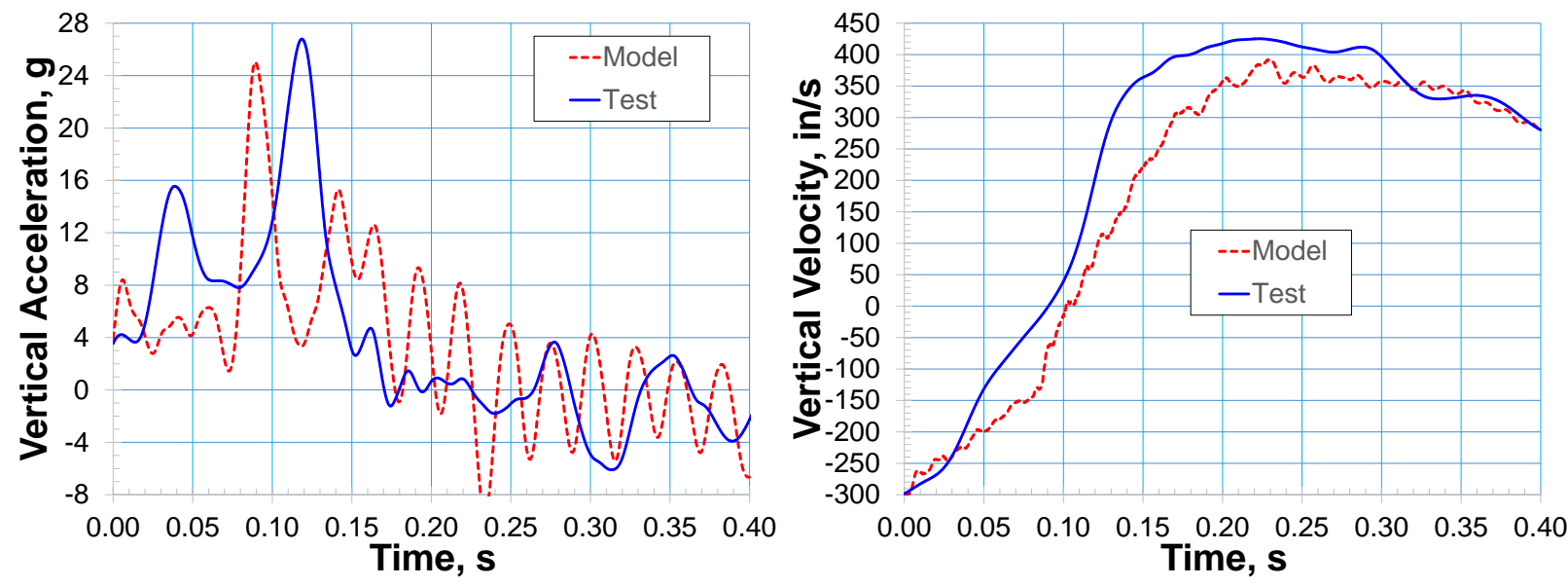

DAS Box
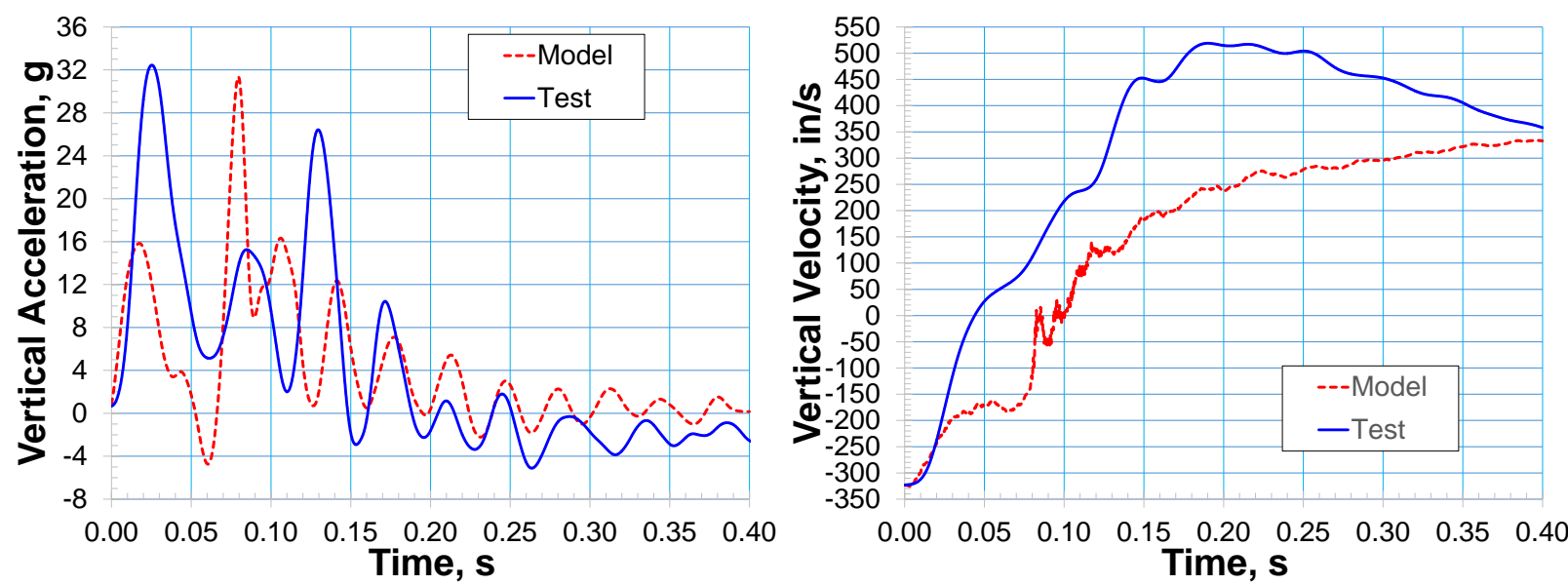

Rear Bulkhead

Figure 16. Test and analysis results of local vertical acceleration and global vertical velocity against time for three locations in Test 3. 


\section{Summary}

Test data from three full-scale aircraft impact tests and corresponding computer simulations analyzed using the ABAQUS explicit finite element software are presented in this paper. Comparisons of test and analysis data included inertial properties, time histories of airframe motion (pitch angle), and time histories of velocities and accelerations. Total weight and axial CG locations for the models were within $0.001 \%$ of the test articles for all three tests. However, the exact weight distribution of a given airframe is uncertain without complete disassembly of the test article. Uncertainty about the weight distribution is a contributing factor in discrepancies in the time history responses. Summaries of the comparison of test and analysis results of vertical delta velocity and vertical acceleration at three airframe locations (left door frame, DAS box, and rear bulkhead) are presented in Tables 9 and 10, respectively.

Table 9. Test and analysis comparisons of vertical delta velocity (percent difference).

\begin{tabular}{|c|c|c|c|}
\hline Location & Test 1 & Test 2 & Test 3 \\
\hline Left Door Frame & 2.1 & -2.3 & -14.2 \\
\hline DAS Box & -2.6 & -8.9 & -4.6 \\
\hline Rear Bulkhead & -2.2 & -0.3 & -31.7 \\
\hline
\end{tabular}

Table 10. Test and analysis comparisons of peak vertical acceleration (percent difference).

\begin{tabular}{|c|c|c|c|}
\hline Parameter & Test 1 & Test 2 & Test 3 \\
\hline Left Door Frame & 27.4 & -50.6 & -4.1 \\
\hline DAS Box & 27.4 & 15.5 & -6.6 \\
\hline Rear Bulkhead & 38.7 & 91.3 & -3.4 \\
\hline
\end{tabular}

The overall findings are:

1) Inertial properties of the models matched the test articles very closely.

2) Kinematic responses of the model were similar to the tests, although a time shift was noted in the soil models.

3) Delta velocities of the model and test were within $10 \%$ for the majority of the airframe locations in all tests.

4) Peak accelerations for the model were usually within 20 to $40 \%$ of the values for the test except at the tail and firewall which were damaged in tests 2 and 3.

5) Uncertainties in weight distribution, unmodeled components, and soil properties contributed to most of the discrepancies between test and analysis. 
Due to the good correlation between analysis and test, the simulation models are suitable for further studies evaluating alternative ELT mounting configurations and for evaluating airframe performance under different impact conditions.

\section{References}

${ }^{1}$ NASA. "NASA's Gantry: Past, Present and Future Asset to Exploration." http://www.nasa.gov/centers/langley/news/factsheets/fs-2007-08-138-larc.html.

${ }^{2}$ Vaughan Jr., V. L., and Alfaro-Bou, E., "Impact Dynamics Research Facility for Full-Scale Aircraft Crash Testing," NASA/TN-D-8179, April 1976.

${ }^{3}$ Littell, J. D., "Crash Tests of Three Cessna 172 Aircraft at NASA Langley Research Center's Landing and Impact Research Facility,” NASA/TM-2015-218987, November 2015.

${ }^{4}$ Castle, C. B., and Alfaro-Bou, E., "Light Airplane Crash Tests at Three Flight-Path Angles," NASA Technical Paper, NASA TP-1210, June 1978.

${ }^{5}$ Hayduk, R. J., "Comparative Analysis of PA-31-350 Chieftain (N44LV) Accident and NASA Crash Test Data," NASA Technical Memorandum TM-80102, October 1979.

${ }^{6}$ Castle, C. B., and Alfaro-Bou, E., "Light Airplane Crash Tests at Three Roll Angles," NASA Technical Paper TP-1477, October 1979.

${ }^{7}$ Vaughan Jr., V. L., and Alfaro-Bou, E., "Light Airplane Crash Tests at Three Pitch Angles," NASA Technical Paper, TP-1481, November 1979.

${ }^{8}$ Vaughan Jr., V. L., and Hayduk, R. J., "Crash Tests of Four Identical High-Wing Single Engine Airplanes," NASA Technical Paper TP-1699, August 1980.

${ }^{9}$ Alfaro-Bou, E., Williams, M. S., and Fasanella, E. L., "Determination of Crash Test Pulses and Their Application to Aircraft Seat Analysis," Society of Automotive Engineers SAE810611, 1981.

${ }^{10}$ Williams, M. S., and Fasanella, E. L., "Crash Tests of Four Low-Wing Twin-Engine Airplanes with Truss-Reinforced Fuselage Structure," NASA Technical Paper, TP-2070, September 1982.

${ }^{11}$ Carden, H. C., "Correlation and Assessment of Structural Airplane Crash Data with Flight Parameters at Impact," NASA Technical Paper TP-2083, November 1982.

${ }^{12}$ Code of Federal Regulations - Title 14: Aeronautics and Space, Part 23: Airworthiness Standards: Normal, Utility, Acrobatic, and Commuter Category Airplanes, 23.562 - Emergency landing dynamic conditions.

${ }^{13}$ Jackson, K. E., Boitnott, R. L., Fasanella, E. L., Jones, L. E., and Lyle, K. H. “A History of Full-Scale Aircraft and Rotorcraft Crash Testing and Simulation at NASA Langley Research Center,” NASA TM-2004-0191337, January 2004. 
${ }^{14}$ Hurley, T. R. and Vandenburg, J. M., editors, "Small Airplane Crashworthiness Design Guide," AGATE Report Reference No. AGATE-WP3.4-034043-036, Simula Technologies Reference No. TR-98099, April 2002.

${ }^{15}$ Thomson, R. G., and Goetz, R. C., "NASA/FAA General Aviation Crash Program - A Status Report," Journal of Aircraft, Vol. 17, No. 8, pp. 584-590, August 1980.

${ }^{16}$ Thomas, M., Chitty, D., Gildea, M., and T'Kindt, C, "Constitutive Soil Properties for Unwashed Sand and Kennedy Space Center,” NASA/CR-2008-215334, July 2008.

${ }^{17}$ Annett, M. S., et al., "Evaluation of the First Transport Rotorcraft Airframe Crash Testbed (TRACT 1) Full-Scale Crash Test," NASA TM-2014-218543, October 2014.

${ }^{18}$ Annett, M. A., Littell, J. D., Stimson, C. M., Jackson, K. E., and Mason, B. H., "Full-Scale Crash Tests and Analyses of Three High-Wing Single Engine Aircraft," Aerospace Structural Impact Dynamics International Conference, Seville, Spain, November 17-19, 2015.

${ }^{19}$ Jackson, K. E. and Fasanella, E. L., "Crash Testing and Simulation of a Cessna 172 Aircraft: Hard Landing onto Concrete," $14^{\text {th }}$ International LS-DYNA Users Conference, Dearborn, MI, June 13-14, 2016.

${ }^{20}$ Fasanella, E. L. and Jackson, K. E., "Crash Testing and Simulation of a Cessna 172 Aircraft: Pitch Down Impact onto Soft Soil," $14^{\text {th }}$ International LS-DYNA Users Conference, Dearborn, MI, June 13-14, 2016.

${ }^{21}$ Mukhopadhyay, V., Hsu, S., Mason, B. H., Sleight, D. W., Jones, W. T., Chu, J., Hicks, M. D., Spangler, J. L., Kamhawi, H., and Dahl, J. L., "Adaptive Modeling, Engineering Analysis and Design of Advanced Aerospace Vehicles," AIAA Paper 2006-2182, 47th AIAA/ASME/ASCE/AHS/ASC SDM Conference, Newport, Rhode Island, May 1-4, 2006.

${ }^{22}$ ABAQUS, ABAQUS User's Manual, Vol III, Version 6.14, Dassault Systèmes Simulia Corp., Pawtucket, RI, 2012.

${ }^{23}$ Society of Automotive Engineers (SAE), Recommended Practice: Instrumentation for Impact Test - Part 1, Electronic Instrumentation, SAE J211/1, March 1995. 